\title{
COMUNICACIÓN
}

\section{NIVELES SÉRICOS REFERENCIALES DE UREA, CREATININA Y ANÁLISIS FISÍCO-QUÍMICO DE LA ORINA DE MONO NOC- TURNO AOTUS NANCYMAE}

\author{
Angelo Vásquez A.', Armando Hung C. ${ }^{2}$, Olga Li E. ${ }^{2}$ y Hugo Gálvez C.
}
Serum urea and creatinine levels and chemical composition of the urine in the night monkey (Aotus nancymae).

\begin{abstract}
Serum and urine samples from 15 male and 15 female captive reared young Aotus nancymae (night monkey, owl monkey or musmuki) were studied in order to determine normal physiological parameters of serum urea and creatinine, as well as urine composition, in animals reared under varying environmental, dietary and management conditions in the Peruvian Amazon. Serum urea and creatinine concentrations were found to be $42.15 \pm 4.76 \mathrm{mg} / \mathrm{dl}$ and $1.35 \pm 0.12 \mathrm{mg} / \mathrm{dl}$. Urine, $\mathrm{pH}$ varied from 6.0 to 7.0 , with specific weights between 1.010 to 1.020 . Negative reactions to protein, bilirubinogen, glucose, ketones and hidden blood were recorded, as well as a 0.2 negative reaction for urobilinogen.
\end{abstract}

Key words: Aotus nancymae, urine analysis, urea and creatinine.

Palabras clave: Aotus nancymae, análisis de orina, urea y creatinina.

El parentesco evolutivo de los primates no humanos con el ser humano es evidente tanto por su extraordinaria semejanza anatómica y comportamiento como similitudes bioquímicas específicas. Por tanto, estos primates sirven de sujetos para estudios comparativos particularmente en relación a las enfermedades del hombre. Debido a su estrecha relación filogenética, los primates no humanos contribuyen en el desarrollo de vacunas como por ejemplo contra la poliomielitis, amplían el conocimiento y comprensión de otras enfermedades como la malaria, fiebre amarilla, el sarampión, la tuberculosis, hepatitis A (Villavicencio et al., 1986), como las enfermedades neoplásicas inducidas por virus, así como el estudio y terapia de enfermedades del ojo, Herpes Simplex II o Herpes Genital, Epstein Barr. (Zamecnik, 1975; Jervis et al.,
1972; Young et al., 1976; Meléndez et al., 1968; Meléndez et al., 1969; Daniel et al., 1974).

El Centro de Reproducción y Conservación de Primates No Humanos (CRCP) ubicado en la ciudad de Iquitos, Perú, realiza la crianza y reproducción de Aotus nancymae, también conocido con los nombres vernáculos de: Musmuqui, mono nocturno, mono lechuza (Hershkovitz, 1983). Esta especie es utilizado para realizar estudios sobre la malaria (Descailleaux et al., 1985), así mismo, para estudios sobre anemia hemolítica, ensayos de una vacuna contra Herpes venéreo, genital o tipo II y Herpes Oncogénico (King, 1994; Suvit, 1987; Chalifoux et al., 1981). Igualmente han contribuido al desarrollo de una vacuna antimalárica (Rieckmann et al., 1980).

\footnotetext{
${ }^{1}$ Práctica privada.

${ }^{2}$ Laboratorio de Patología Clínica, FMV - UNMSM

${ }^{3}$ Laboratorio de Vida Silvestre y Recursos Naturales, EE -IVITA, Iquitos, FMV-UNMSM
} 
Estudios fisiológicos como la determinación de los valores séricos de urea, creatinina y características físico-químicas de la orina en estos monos han sido realizados en otros lugares, bajo condiciones climáticas, alimenticias y de manejo diferente a la región de la Selva peruana.

Siendo esta especie de importancia biomédica, es indispensable determinar algunos parámetros bioquímicos referenciales en Aotus nancymae de apariencia normal, así como conocer las características de su orina como parte de la funcionalidad renal. Por ello, el objeto del presente trabajo fue la determinación de los niveles séricos de urea, creatinina y características físico-químicas de la orina contribuyendo al conocimiento de la funcionalidad renal de esta importante especie.

El presente trabajo se realizó en el Centro de Reproducción y Conservación de Primates No Humanos (CRCP), ubicado en la Estación Experimental de Iquitos del Instituto Veterinario de Investigaciones Tropicales y de Altura (IVITA).

La determinación físico-química de la orina se realizó en el mismo instante de la recolección. La determinación de los niveles de urea y creatinina séricos fueron analizados en el Laboratorio de Patología Clínica de la Facultad de Medicina Veterinaria de la Universidad Nacional Mayor de San Marcos.

Las condiciones ambientales de la zona fueron: clima: trópico húmedo, temperatura media de $26.3^{\circ} \mathrm{C}$, precipitación total anual de $402.88 \mathrm{~mm}$, humedad relativa de $89.61 \%$.

Los animales fueron alimentados con cuatro galletas (11g/día), elaboradas en la panadería del mismo CRCP. También se les proporcionó plátano "maduro" pelado y cortado en rodajas, ocasionalmente naranja y el agua se proporcionó ad libitum.
Se utilizaron 30 animales sub-adultos ( 7 meses a 2 años) nacidos en cautiverio en el CRCP y distribuidos en dos grupos: grupo A:15 Aotus hembras y grupo B:15 Aotus machos.

Cada animal previo a la toma de muestra fue sometido a un examen clínico, hallándolos aparentemente en buen estado de salud.

Para la obtención de las muestras de sangre se anestesió a los animales con Clorhidrato de Ketamina a razón de $8 \mathrm{mg} / \mathrm{kg}$. de peso vivo, luego se procedió a extraer sangre $(2 \mathrm{ml})$ de la vena femoral con aguja $\mathrm{N}^{\circ} 22$ estéril y se le depositó en tubos estériles secos sin anticoagulante.

Para la recuperación post-anestésica, se ubicaron a los animales en nidales a los cuales se les tapó el orificio de salida para que los animales no salieran y se hicieran daño, pues todavía se encontraban con los efectos de la Ketamina y también para hacer la recolección de la orina.

El diseño de estos nidos tiene como base una malla metálica que deja pasar las excretas. Por debajo de esta malla metálica se colocó una malla mosquitero que sólo dejo pasar la orina y no las heces. Bajo la malla mosquitero se puso un plástico en forma de embudo donde se recepcionó la orina.

Para determinar los niveles séricos de urea se utilizó el kit comercial Uremia, basado en que la ureasa descompone específicamente a la urea produciendo dióxido de carbono y amoniaco; éste reacciona con fenol e hipoclorito en medio alcalino produciendo azul de indofenol que se determina colorimétricamente.

Para determinar los niveles séricos de creatinina se utilizó el kit comercial Creatinina, cuyo fundamento es que la creatinina reacciona con el picrato alcalino en medio tamponado, previa desproteinización con ácido pícrico, obteniéndose un cromógeno que se mide a $510 \mathrm{~nm}$. 
Para el análisis de la orina, se sumergió la tira reactiva Ames-Bayer en la orina retirándola inmediatamente y eliminando el exceso de la misma. Este reactivo proporciona información en un tiempo que varía de 30" a 2' referente al metabolismo de carbohidratos, función hepática y renal, balance ácido base e infecciones del tracto urinario.

A los resultados obtenidos de urea y creatinina se le aplicaron las siguientes pruebas: Media, Rango e Intervalo de Confianza.

Los valores obtenidos para los niveles de urea en Aotus sub-adultos (Cuadro 1) fueron mayores a los obtenidos por Baer (1994); así mismo, fueron mayores a los obtenidos por Murray (1986) para Aotus trivirgatus (29.96 mg/dl); comparando los resultados del presente estudio con resultados de otros autores para otras especies de primates se encontró que fueron menores a los reportados por Karesh y Olson (1985) para primates como Varecia variegata juvenil (51.57 mg/ dl), pero muy similares para Varecia rubra juveniles (46.07 mg/dl).
Por otro lado, los resultados de urea en Aotus fueron mayores a los reportados por Almirral et al. (1999) para el hombre (35.8 $\pm 4 \mathrm{mg} / \mathrm{dl}$ ); y menores (20 a $40 \mathrm{mg} / \mathrm{dl}$ ) a los reportados por Glaxo (2000).

Los valores obtenidos de creatinina sérica en Aotus sub-adultos (Cuadro 1) fueron superiores a los obtenidos por Baer (1994), y mayores a los reportados por Karesh y Olson (1985) en otra especie de primates como Varecia variegata juveniles $(0.65 \mathrm{mg} / \mathrm{dl})$ y para Varecia rubra juveniles $(0.79 \mathrm{mg} / \mathrm{dl})$.

Los resultados de creatinina fueron, muy similares a los hallados por Almirral et al. (1999) para el hombre $(1.4 \pm 0.27 \mathrm{mg} /$ dl).

En la orina el pH fue de 6.0 a 7.0; gravedad específica de 1,010 a 1,020; leucocitos negativos; nitritos negativo; urobilinógeno 0.2 ; proteínas negativo; sangre oculta negativo; cetóna negativo; bilimubina negativo y glucosa negativo. El análisis físico-químico de la orina corrobora los resultados obtenidos por Baer (1994).

Cuadro 1. Resultados del análisis de urea $(\mathrm{mg} / \mathrm{dl})$ y creatinina $(\mathrm{mg} / \mathrm{dl})$ en suero sanguíneo en Aotus nancymae.

\begin{tabular}{lllcc}
\hline & $\mathrm{n}$ & $\begin{array}{l}\text { Machos } \\
\mathrm{X} \pm \mathrm{IC}^{*}\end{array}$ & $\mathrm{n}$ & $\begin{array}{l}\text { Hembra } \\
\mathrm{X} \pm \mathrm{ICs}\end{array}$ \\
\hline Urea & 15 & $40.7 \pm 7.47$ & 15 & $43.6 \pm 6.43$ \\
Creatinina & 15 & $1.45 \pm 0.16$ & & $1.25 \pm 0.18$ \\
\hline
\end{tabular}

$* \mathrm{X} \pm \mathrm{IC}$ : Promedio \pm intervalo de confianza. 
1. Almirral, J.; M. S. Jurkiewicz, Fabregas - Martínez y M. García. 1999. Desarrollo y validación de un biosensor biparamétrico de urea y creatinina para la monitorización de la sesión de hemodiálisis. Originales. Volumen XIX. Número 4.

2. Baer, J. F. 1994. Aotus: The Owl Monkey. En: Husbandry and medical management of the owl monkey. Cap. 5, Academic Press Inc.

3. Chalifoux, L. V.; R. T. Bronson, B. J. Sehgal, B. J. Blake y N. W. King. 1981. Nephritis and hemolytic Anemia in Owl Monkeys (Aotus Trivirgatius). Vet. Pathol. 18 (Supple. 6); p. 23-37

4. Daniel, M. D.; L. V. Meléndez, R. D. Hent, N. W. King, M. Anver, C.E.G. Fraser, H. Barahona y R. B. Baggs. 1974. Herpesvirus saimiri. VII. Induction of malignant lymphoma in new zealand white rabbits, J. Natl cancer Inst. 53:1803-1807.

5. Descailleaux, J.; R. Fujita, L.A. Rodríguez, $R$. Aquino y F. Encarnación. 1985. Rearreglos cromosómicos y variabilidad cariotípica del género Aotus (Cebidae: Platyrrhini).

6. Glaxo W. 2000. Vademecum. Tablas de uso clínico. Fuente: http://www. Glaxowelcome.com.mx/vademecum/ analisis. Html

7. Hershkovitz, P., 1983. Two new species of nigth monkey. Genus Aotus: A preliminary report on Aotus taxonomy. American Journal of Primatology. 4: 209 443.

8. Jervis, H.R.; S. Helmuth., A.J. Johnson y B. T. Wellde. 1972. The American Journal of Tropical. Medicine and Hygiene. Vol. 21, $\mathrm{N}^{\circ} 3$. Experimental Infection With.
9. Karesh, W.B. y T.P. Olson. 1985. Hematology and serum chemistry values of juvenile and adult Ruffed Lemurs (Varecia variegata). Short Papers. J. Med. Primatol. 14: 5-12.

10. King, N.W. 1994. The Owl Monkey in Oncogenic Virus Research. En: Aotus: The Owl Monkey. Cap. 9, ed., Janet F. Baer; Richard E. Weller; Ibulaimu Kakoma. Academic Press, Inc.

11. Meléndez, L. V., M.D. Daniel, R. D. Hent y F. G. García. 1968. An apparently new herpes virus from primary Kidney culturales of the squirrel monkey (Saimiri sciureus). Lab. Animo care 18:374-381.

12. Meléndez, L. V.; Hunt, M. D. Daniel, F. G. García y C.E.G. Fraser. 1969. Herpes virus saimiri II. Experimentally induced malignant lymphona inprima-les, Lab. Anim Care 19:378-386.

13. Murray, E.F. 1986. Zoo and wild animal medicine. 2da. ed., Editorial OPS/ OMS. WB Saunders Company. Philadelphia.

14. Rieckmann, K.; J.E.K. Maarchall y D. Hafner. 1980. Breeding of Aotus Monkey for Human Malaria Research. Bull Pan American Health Organization, 14(3).

15. Suvit, A. 1987. Renal clearance, tubular reabsorption and urinary excretion of albumin in mon keys infected with plasmodium knowlesi. Vol, $18 \mathrm{~N}^{\circ} 1$ March.

16. Villavicencio, E.; E. Montoya y $C$. Málaga. 1986. Aspectos reproductivos y sanitarios de la colonia de Saguinus mystax del centro de reproducción y conservación de primates no-humanos. Presentado en el taller sobre la crianza controlada de primates no-humanos en su propio hábitat. Iquitos, Perú, p. 24-26 nov. 86. 
17. Young, M.D.; R. Rossan y D. Baer, 1976. Gorgas Memorial Laboratory. Balboa Heights, Canal Zone. Malaria. Comparative Pathology Bulletin. 8:1.

18. Zamecnik, C.P. 1975. Importancia de los primates Americanos no humanos para la salud humana y las investi- gaciones biomédicas. Primera Conferencia Interamericana sobre la conservación y utilización de primates Americanos no humanos en las investigaciones biomédicas. Publicación científica 317 - OPS/OMS. Lima-Perú, 2-4 junio de 1975 . 